\title{
Telbivudine for the treatment of chronic hepatitis B in HBeAg-positive patients in China: a health economic analysis
}

\author{
S. Banerjee', P. Gunda ${ }^{1}$, R. F. Drake ${ }^{2}$ and K. Hamed ${ }^{3 *}$ (1)
}

\begin{abstract}
Background: Nucleos(t)ide analogs (NUCs) are the standard of care for chronic hepatitis B (CHB). The present analysis aimed to determine the cost effectiveness of NUCs in Chinese healthcare settings.

Methods: A Markov model was used to simulate two therapeutic strategies for a hypothetical patient cohort diagnosed with hepatitis $\mathrm{B}$ e antigen-positive $\mathrm{CHB}$, unwilling or unable to receive interferon therapy, and about to start treatment with any NUC. The first strategy included NUC monotherapy without sequencing (telbivudine [LDT], entecavir [ETV], tenofovir [TDF], lamivudine [LAM], adefovir dipivoxil [ADV], and combination therapies of either LDT and ADV or LDT and TDF, followed by best supportive care [BSC]). The second strategy included sequential therapies of individual NUCS: LAM $\rightarrow$ ADV, ADV $\rightarrow$ LAM, LDT $\rightarrow$ ADV, and ETV $\rightarrow$ ADV, followed by BSC. The analysis included two scenarios: with and without costs due to nephrotoxicity. Renal impact was quantified as costs alone, without consideration for quality of life decrements.
\end{abstract}

Results: When renal impact was not considered, without treatment sequencing, LDT was cost effective compared with other NUCs. Amongst the strategies with sequencing, LDT $\rightarrow$ ADV was cost effective. The results were similar when renal impact was considered. However, LDT strategy demonstrated better cost effectiveness. In probabilistic sensitivity analysis, in both scenarios, LDT $\rightarrow$ ADV sequence was cost effective with $51 \%$ probability even at willingness to pay of $\$ 20,000$.

Conclusion: Use of LDT, as compared with other NUCs, is cost effective in CHB treatment in Chinese healthcare settings. Considering the detrimental renal impact, overall costs for all treatment options were increased. However, the increase for LDT was comparatively small.

Keywords: Cost effectiveness, Chronic hepatitis B, Renal impairment, Telbivudine

\section{Background}

Approximately 240 million people worldwide are chronically infected with the hepatitis B virus (HBV) (World Health Organization 2015). China has the highest burden, with an estimated 100 million people with chronic hepatitis $\mathrm{B}(\mathrm{CHB})$, translating into approximately 300,000 annual deaths from HBV-related liver complications (Vellozzi and Averhoff 2016) such as end-stage liver disease and hepatocellular carcinoma (HCC) (Ng et al. 2013;

\footnotetext{
*Correspondence: kamal.hamed@novartis.com

${ }^{3}$ Novartis Pharmaceuticals Corporation, East Hanover, NJ, USA

Full list of author information is available at the end of the article
}

Robotin 2011). Eradication of HBV is a national priority in China (Yu et al. 2014), and various healthcare programs have been designed to address this imperative. In 2010, the Chinese Ministry of Science and Technology commissioned a project to evaluate the economic burden of HBV-related diseases (National Health and Family Planning Commission of the People's Republic of China 2015).

Nucleos(t)ide analogs (NUCs) represent the mainstay of pharmacological treatment for $\mathrm{CHB}$ (Wong et al. 2014). Five NUCs, namely telbivudine [LDT], entecavir [ETV], tenofovir [TDF], lamivudine [LAM], and adefovir dipivoxil [ADV], are currently being used for the 
treatment of CHB worldwide (Deray et al. 2015). NUCs primarily act by suppressing HBV replication, thereby minimizing the risk of liver disease progression and subsequent complications, including hepatic decompensation and HCC, in both pre-cirrhotic and cirrhotic patients (Fung et al. 2011). Considering that NUC treatment does not eradicate the virus, most patients require long-term treatment. NUCs are generally safe and well tolerated, but nephrotoxic effects have been reported with long-term treatment. Renal toxicity develops because of accumulation of NUC metabolites in renal tubular cells. Clinical evidence suggests that nephrotoxicity is more frequent with ADV, followed by TDF (Deray et al. 2015). Nephrotoxicity clinically manifests as a decrease in glomerular filtration rate (GFR) and is more common in patients older than 50 years and those with baseline renal insufficiency, hypertension, and/or diabetes mellitus. The Chinese guidelines provide recommendations on the selection of effective treatments for $\mathrm{CHB}$ patients, but these are not driven by pharmacoeconomic evidence (Chinese Society of Hepatology and Chinese Society of Infectious Diseases and Chinese Medical Association 2011; Zhang et al. 2015). In spite of extensive use in clinical practice, the cost of NUCs is the primary factor that drives their real-world use as well as adherence among patients (Fung et al. 2011). This is particularly seen in countries with limited healthcare resources, such as China. The Chinese healthcare setting is evolving from a resource-constrained scenario to a modern healthcare framework (Blumenthal and Hsiao 2015). In such a setting, treatment strategies driven by cost-effectiveness evidence may help optimize case management of $\mathrm{CHB}$ in hepatitis B e antigen (HBeAg)-positive patients in China.

Multiple economic analyses have been conducted to compare the available NUCs in various settings (Almeida et al. 2012; He et al. 2012; Spackman and Veenstra 2008; Wu et al. 2010; Zhang et al. 2015). Nevertheless, the previous studies did not model the effects of renal impairment, resistance, sequencing of treatment, or long-term disease progression. Hence, cost-effectiveness analyses are needed to determine the most cost-effective NUC(s) for CHB treatment. The objective of the current analysis was to evaluate the cost effectiveness of NUCs using two treatment strategies from the perspective of the Chinese healthcare system.

\section{Methods}

\section{Treatment strategies}

The first strategy included NUC treatment options without sequencing: LDT, ETV, TDF, LAM, ADV, combination therapies of LDT and ADV or LDT and TDF, each followed by best supportive care (BSC). The second strategy included treatment sequencing: LAM $\rightarrow$ ADV,
$\mathrm{ADV} \rightarrow \mathrm{LAM}, \mathrm{LDT} \rightarrow \mathrm{ADV}$, and $\mathrm{ETV} \rightarrow \mathrm{ADV}$, followed by BSC. It was assumed that patients with HBV resistance to the first NUC would be switched to the second NUC, and subsequently to BSC, in the second strategy.

\section{Model structure and description}

A de novo Markov transition model was developed in MS Excel $2010^{\circledR}$ to estimate the cost effectiveness of NUCs in the treatment of CHB. This model assumed that patients were always in one of the finite number of health states, referred to as Markov states. Patients were transitioned among the Markov states according to a set of transition probabilities that depended only on the current health state. Patients stayed in the same health state but moved to the next-line treatment if they developed resistance to a treatment. The present health economic model consisted of the following eight health states (Fig. 1):

1. Cured (generally assumed as $\mathrm{HBeAg}$ negative or hepatitis B surface antigen [HBsAg] negative and not corresponding to the clinical definition of cure)

2. Inactive carrier ( $\mathrm{HBsAg}$ positive and $\mathrm{HBeAg}$ negative)

3. $\mathrm{CHB}$

4. Compensated cirrhosis $(\mathrm{CC})$

5. Decompensated cirrhosis (DC)

6. HCC

7. Liver transplant (LT) year 1 (LT Year 1; in the year of transplantation)

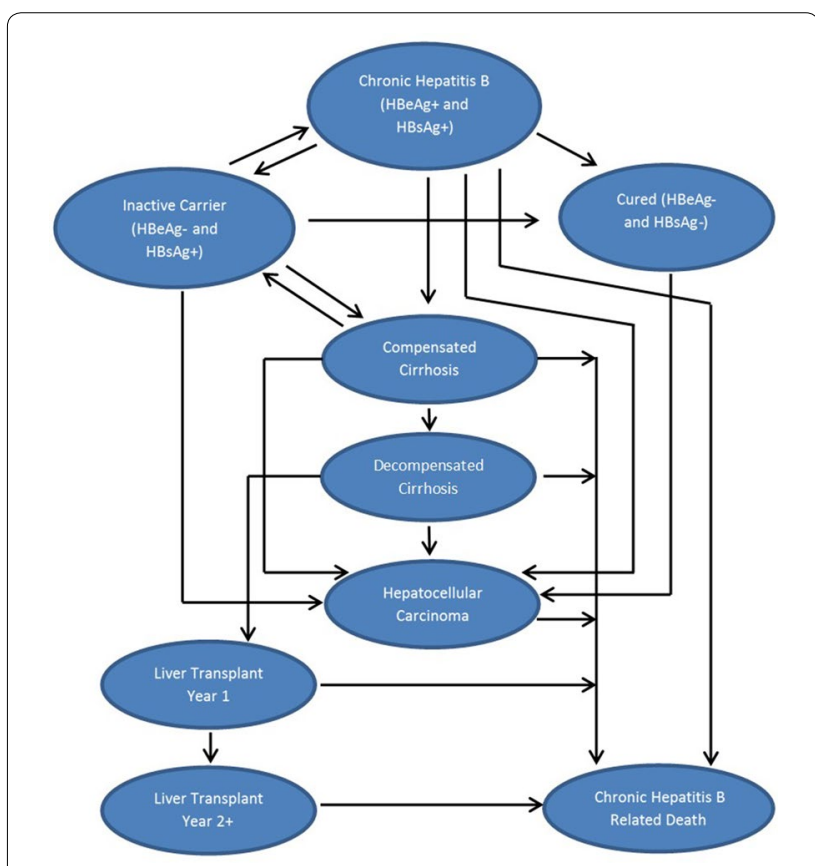

Fig. 1 Schematic representation of the Markov model structure 
8. Liver transplant year 2 onwards (LT Year 2+; after first year of transplantation)

Two additional absorbing health states were considered: CHB-related death and death due to non-CHB causes. Transitions among the health states were determined based on disease progression and treatment efficacy (Tables 1,2). The cost-effectiveness analysis used a cycle length of 1 year and followed the patients for their entire life. The underlying assumption while constructing the Markov trace for $\mathrm{CHB}$ patients was that HBV resistance would not develop in patients who move to the inactive carrier state (with typically low HBV DNA levels) in the same cycle and/or who remain in the inactive carrier state. Substantial clinical evidence indicates that on-treatment HBV DNA levels are predictive of virologic resistance in CHB patients (Biazar et al. 2015; Chang 2009). Low rates of resistance were reported during the first and second years of telbivudine therapy in patients who achieved undetectable serum HBV DNA levels at treatment week 24 (Liaw 2009; Liu 2013). Furthermore, undetectable HBV DNA after 2 years of telbivudine treatment was also reported to be associated with low telbivudine resistance (Zeuzem et al. 2009).

In the deterministic analysis, total discounted costs and total discounted quality-adjusted life-years (QALYs) were estimated. Since multiple treatment strategies were compared, results were depicted on a cost-effectiveness frontier. Apart from the deterministic analysis, a probabilistic sensitivity analysis (PSA) was also performed. For the PSA, $\beta$ distribution was used for transition probabilities, treatment effects, reactivation rates, utilities, and viral resistance, whereas $\gamma$ distribution was used for average eGFR and costs, and normal distribution for change in eGFR.

Patients discontinued the treatment if 1 year had elapsed after converting to HBeAg-negative status as per clinical guidelines (Sarin et al. 2016). The analyses involved two scenarios; the first scenario did not include the detrimental renal impact of the NUCs, while the second scenario included the nephrotoxic effects of the treatments. Renal impact was quantified in terms of costs only, and any quality of life decrements due to renal impact were not considered in the analysis.

\section{Model settings \\ Population}

The model simulated the experiences of a hypothetical cohort of patients who were diagnosed with HBeAgpositive $\mathrm{CHB}$, were unwilling or unable to receive interferon therapy, and were about to start treatment with one of the NUCs. If patients developed resistance to a treatment, they were assumed to stay in the same health state but move to the next-line treatment. The starting age of the cohort was 31 years, and $75 \%$ were males. The model was developed with a cycle length of 1 year and followed patients for a lifetime.

\section{Discounting}

Costs and outcomes were discounted at $3.5 \%$ per annum.

\section{Length of consolidation treatment after $\mathrm{HBeAg}$ seroconversion}

The model determined the impact on cost-effectiveness results when the treatment was continued for a minimum of 1 year after HBeAg seroconversion (as per the AsianPacific clinical practice guidelines on the management of hepatitis B (Sarin et al. 2016)). Although HBsAg seroclearance is the ideal endpoint, it is only achievable in up to $12 \%$ of patients after long-term NUC treatment (Yuen et al. 2016). Therefore, finite therapy (treatment of 1 year) based on HBeAg seroconversion, which represents the current standard-of-care in China, was employed in the model.

\section{Perspective}

The model adapted the perspectives of the Chinese healthcare settings.

\section{Model inputs}

Efficacy values specific to the Chinese population were included wherever possible for all the model inputs.

\section{Treatment regimens}

Various treatment strategies currently employed for the management of $\mathrm{CHB}$ patients in China were used (Zhang et al. 2015) (Table 3).

\section{Efficacy inputs}

HBsAg and HBeAg seroconversions with all treatments were obtained from the published literature (Table 3). The model included reactivation rate, i.e. patients transitioning from the inactive carrier state ( $\mathrm{HBeAg}$ negative and $\mathrm{HBsAg}$ positive) to $\mathrm{CHB}$ status (HBeAg positive and HBsAg positive). This reactivation rate was modeled only for year 1 , during which it is expected to be maximum. These values were obtained from the published literature (Table 3). It was assumed that the first NUC treatment would lower the occurrence of cirrhosis by $40 \%$ in comparison with BSC (Shepherd et al. 2006). The resistance rates for the NUCs used in the model, along with their sources, are provided in Table 4 (Liaw et al. 2009; Zhang et al. 2015).

\section{Long-term disease progression}

For BSC, long-term transition to more severe health states (as stated below) were obtained from a recent publication (Zhang et al. 2015). As long-term data on 


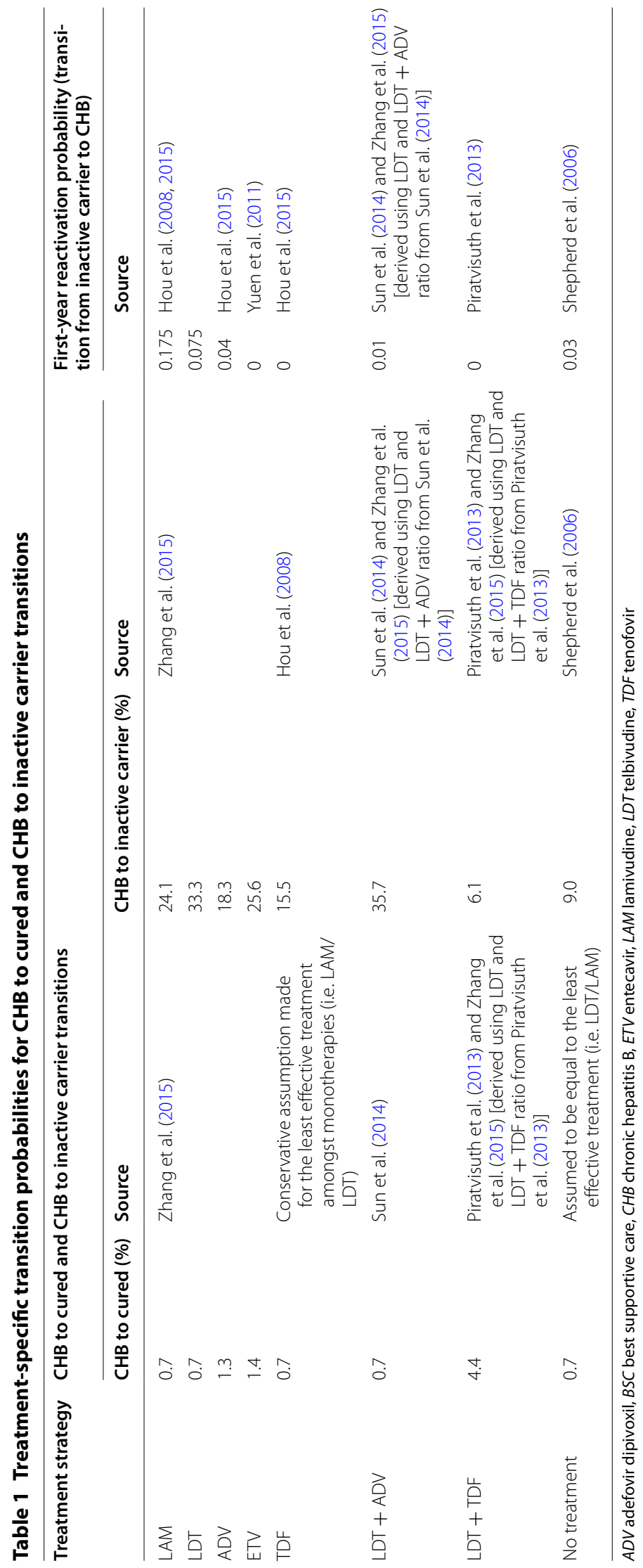


Table 2 Other transition probabilities used in model

\begin{tabular}{|c|c|c|}
\hline \multicolumn{3}{|c|}{ Treatment independent transitions } \\
\hline Transition & Probability & Source \\
\hline Inactive carrier to cured & 0.020 & Shepherd et al. (2006) \\
\hline Inactive carrier to $\mathrm{CHB}$ & 0.030 & \\
\hline Inactive carrier to CC & 0.009 & \\
\hline Cured to HCC & 0.00005 & Zhang et al. (2015) \\
\hline Inactive carrier to HCC & 0.002 & \\
\hline $\mathrm{CHB}$ to $\mathrm{CC}$ & 0.010 & \\
\hline $\mathrm{CHB}$ to $\mathrm{HCC}$ & 0.004 & \\
\hline CHB to Dead & 0.009 & \\
\hline CC to inactive carrier & 0.090 & Shepherd et al. (2006) \\
\hline $\mathrm{CC}$ to $\mathrm{HCC}$ & 0.018 & Zhang et al. (2015) \\
\hline CC to dead & 0.025 & \\
\hline DC to HCC & 0.091 & \\
\hline DC to LT Year 1 & 0.050 & \\
\hline HCC to Dead & 0.520 & \\
\hline \multicolumn{3}{|c|}{ Treatment specific other transitions } \\
\hline Transition & Probability for NUCs & Source \\
\hline$C C$ to $D C$ & $0.00936(R R=0.36)$ & Shepherd et al. (2006) \\
\hline DC to dead & $0.052(\mathrm{RR}=0.50)$ & \\
\hline LT Year 1 to dead & $0.012(R R=0.1)$ & \\
\hline LT Year 2+ to dead & $0.0057(\mathrm{RR}=0.1)$ & \\
\hline Transition & Probability for BSC & Source \\
\hline CC to DC & 0.026 & Zhang et al. (2015) \\
\hline DC to dead & 0.104 & \\
\hline LT Year 1 to dead & 0.120 & \\
\hline LTYear $2+$ to dead & 0.057 & Shepherd et al. (2006) \\
\hline
\end{tabular}

$A D V$ adefovir dipivoxil, $B S C$ best supportive care, $C C$ compensated cirrohoiss, $C H B$ chronic hepatitis $B, D C$ decompensated cirrhosis, ETV entecavir, $H C C$ hepatocellular carcinoma, $L A M$ lamivudine, $L D T$ telbivudine, $L T$ liver transplant, NUCs nucleos(t)ide analogs, $R R$ relative risk, TDF tenofovir

the effects of NUCs were not available, the transitions below were considered to be similar to those with BSC.

- CC to DC

- DC to dead

- LT Year 1 to dead

- LT Year 2+ to dead

\section{Renal impairment inputs}

The model also captured the effects of long-term use of NUCs on renal function. The annual changes in eGFR by treatment are listed in Table 5, along with their sources. In the analysis, an average of available data was extrapolated for follow-up years. Annual changes in eGFR were used to estimate the eGFR of a cohort at the end of each cycle for a particular treatment regimen, and this eGFR was then used to estimate renal costs. All patients were assumed to start with a chronic kidney disease (CKD) stage 1 and an eGFR of $108.1 \mathrm{~mL} / \mathrm{min} / 1.73 \mathrm{~m}^{2}$ (i.e. normal eGFR) (Tsai et al. 2016). When eGFR is less than or equal to $15 \mathrm{~mL} / \mathrm{min} / 1.73 \mathrm{~m}^{2}$, the patient would be considered to go on dialysis and remain on dialysis until renal transplantation (Tattersall et al. 2011). In the base case, the waiting time for a kidney transplant was assumed to be 3 years, and post-transplantation the patient was assumed to move to CKD stage 1 .

\section{Utility inputs}

Utilities were assigned for each health state (Table 6). Utility inputs for the health states were derived from a previous study by Levy et al. (2008) that evaluated utilities using a standard gamble technique in the Chinese population.

\section{Mortality inputs}

A life table for the different age groups in China was derived from the World Health Organization website (World Health Organization 2012) and was used to calculate all-cause mortality for the model. 
Table 3 Treatment regimens used in the model

\begin{tabular}{|c|c|}
\hline Treatment strategy & $\begin{array}{l}\text { Treatment explanation ("A } \rightarrow B \text { " indicates after developing resistance to treatment } A \text {, patients move to treatment } B \text {; } \\
\text { " }+ \text { " indicates combination therapy) }\end{array}$ \\
\hline BSC & No antiviral drug treatment \\
\hline $\mathrm{LAM} \rightarrow \mathrm{BSC}$ & LAM as first-line therapy, followed by BSC as second- and third-line therapy \\
\hline $\mathrm{LDT} \rightarrow \mathrm{BSC}$ & LDT as first-line therapy, followed by BSC as second- and third-line therapy \\
\hline $\mathrm{ADV} \rightarrow \mathrm{BSC}$ & ADV as first-line therapy, followed by BSC as second- and third-line therapy \\
\hline $\mathrm{ETV} \rightarrow \mathrm{BSC}$ & ETV as first-line therapy, followed by BSC as second- and third-line therapy \\
\hline $\mathrm{TDF} \rightarrow \mathrm{BSC}$ & TDF as first-line therapy, followed by BSC as second- and third-line therapy \\
\hline $\mathrm{LDT}+\mathrm{ADV} \rightarrow \mathrm{BSC}$ & Combination therapy of LDT and ADV as first-line therapy, followed by BSC as second- and third-line therapy \\
\hline $\mathrm{LDT}+\mathrm{TDF} \rightarrow \mathrm{BSC}$ & Combination therapy of LDT and TDF as first-line therapy, followed by BSC as second- and third-line therapy \\
\hline $\mathrm{LAM} \rightarrow \mathrm{ADV} \rightarrow \mathrm{BSC}$ & LAM as first-line therapy, followed by ADV as second-line therapy and BSC as third-line therapy \\
\hline $\mathrm{ADV} \rightarrow \mathrm{LAM} \rightarrow \mathrm{BSC}$ & ADV as first-line therapy, followed by LAM as second-line therapy and BSC as third-line therapy \\
\hline $\mathrm{LDT} \rightarrow \mathrm{ADV} \rightarrow \mathrm{BSC}$ & LDT as first-line therapy, followed by ADV as second-line therapy and BSC as third-line therapy \\
\hline $\mathrm{ETV} \rightarrow \mathrm{ADV} \rightarrow \mathrm{BSC}$ & ETV as first-line therapy, followed by ADV as second-line therapy and BSC as third-line therapy \\
\hline
\end{tabular}

$A D V$ adefovir dipivoxil, $B S C$ best supportive care, ETV entecavir, $L A M$ lamivudine, $L D T$ telbivudine, $T D F$ tenofovir

Table 4 Resistance profiles of antiviral therapies

\begin{tabular}{|c|c|c|c|c|c|c|c|}
\hline \multicolumn{8}{|c|}{ Resistance profiles } \\
\hline Year & ADV & LDT & LAM & ETV & TDF & $\mathrm{LDT}+\mathrm{ADV}$ & $\mathrm{LDT}+\mathrm{TDF}$ \\
\hline 1 & $0 \%$ & $3 \%$ & $9 \%$ & $0 \%$ & $0 \%$ & $3 \%$ & $3 \%$ \\
\hline 2 & $2 \%$ & $15 \%$ & $22 \%$ & $1 \%$ & $0 \%$ & $15 \%$ & $15 \%$ \\
\hline 3 & $5 \%$ & $15 \%$ & $22 \%$ & $3 \%$ & $0 \%$ & $15 \%$ & $15 \%$ \\
\hline 4 & $8 \%$ & $15 \%$ & $22 \%$ & $3 \%$ & $0 \%$ & $15 \%$ & $15 \%$ \\
\hline \multirow[t]{2}{*}{5} & $8 \%$ & $15 \%$ & $22 \%$ & $3 \%$ & $0 \%$ & $15 \%$ & $15 \%$ \\
\hline & GLOB & & & Zhang et al. (2015) & Piratvisuth et al. (2013) & $\begin{array}{l}\text { Conservative assumption } \\
\text { of resistance of same } \\
\text { as LDT }\end{array}$ & $\begin{array}{l}\text { Conservative assumption of } \\
\text { resistance of same as LDT }\end{array}$ \\
\hline
\end{tabular}

$A D V$ adefovir dipivoxil, $E T V$ entecavir, $L A M$ lamivudine, $L D T$ telbivudine, $T D F$ tenofovir

Table 5 Changes in eGFR by year for various treatment options (variation per year compared with previous year)

\begin{tabular}{lrrrrrrr}
\hline Treatment & Year $\mathbf{1}$ & Year $\mathbf{2}$ & Year $\mathbf{3}$ & Year $\mathbf{4}$ & Year $\mathbf{5}$ & Source & Year $>\mathbf{5}$ \\
\hline TDF & -6.40 & 0.70 & 0.70 & 0.70 & 0.70 & Tsai et al. (2016) & -0.72 \\
LDT & 9.57 & 5.86 & 10.81 & 10.81 & 10.81 & Qi et al. (2015) & -1.57 \\
ETV & 0.00 & 1.99 & -3.27 & -3.27 & -3.27 & Qi et al. (2015) & -3.40 \\
LAM & -4.72 & -5.40 & -2.29 & -2.29 & -2.29 & Qi et al. (2015) & -4.57 \\
ADV & -6.92 & -4.72 & -3.74 & -3.74 & -3.74 & Qi et al. (2015) & 9.57 \\
LDT + ADV & 9.57 & 5.86 & 10.81 & 10.81 & 10.81 & Assumed to be same as LDT & 9.57 \\
LDT + TDF & 9.57 & 5.86 & 10.81 & 10.81 & 10.81 & & -0.65 \\
BSC & -0.69 & -0.38 & -0.73 & -0.73 & -0.73 & Qi et al. (2015) & \\
\hline
\end{tabular}

eGFR was measured in $\mathrm{mL} / \mathrm{min} / 1.73 \mathrm{~m}^{2}$. For the eGFR changes, for each treatment, the last available observations were carried forward till year 5

$A D V$ adefovir dipivoxil, $B S C$ best supportive care, eGFR estimated glomerular filtration rate, ETV entecavir, $L A M$ lamivudine, $L D T$ telbivudine, $T D F$ tenofovir

\section{Cost inputs}

The various types of costs included were health state costs, drug costs, costs related to the management of renal impairment, and diagnostic costs (Table 6). The health state costs were primarily obtained from a study by Zhang et al. (2015). The drug costs were obtained from the IMS PADDS 2015 database. At the time of this evaluation, ETV, LAM, and ADV were available as generics, and hence, their generic costs were included, whereas for LDT and TDF, the branded costs were used. All values 
Table 6 Cost inputs used in the China seroconversion model

\begin{tabular}{|c|c|c|c|c|}
\hline Cost parameter & Annual cost (\$) & Source & Utility & Source \\
\hline \multicolumn{5}{|l|}{ Heath state costs } \\
\hline Cured (HBsAg negative) & 1315.9 & \multirow[t]{8}{*}{ Zhang et al. (2015) } & 0.710 & \multirow[t]{8}{*}{ Levy et al. (2008 } \\
\hline Inactive carrier & 2237.5 & & 0.710 & \\
\hline Chronic hepatitis B & 2237.5 & & 0.520 & \\
\hline Compensated cirrhosis & 3468.5 & & 0.570 & \\
\hline Decompensated cirrhosis & 6449.3 & & 0.260 & \\
\hline Hepatocellular carcinoma & 9179.5 & & 0.310 & \\
\hline Liver transplant year 1 & $57,765.5$ & & 0.410 & \\
\hline Liver transplant year $2+$ & 9626.9 & & 0.550 & \\
\hline \multicolumn{5}{|l|}{ Drug costs } \\
\hline LAM & 710.41 & \multirow{2}{*}{\multicolumn{3}{|c|}{$\begin{array}{l}\text { IMS PADDS database, cost of LAM is derived from Zhang et al. (2015); inflation } \\
\text { adjusted }\end{array}$}} \\
\hline ADV & 579.54 & & & \\
\hline LDT & 1132.41 & & & \\
\hline ETV & 1073.10 & & & \\
\hline TDF & 2636.08 & & & \\
\hline LDT + ADV & 1711.95 & & & \\
\hline $\mathrm{LDT}+\mathrm{TDF}$ & 3768.49 & & & \\
\hline BSC & NA & & & \\
\hline $\begin{array}{l}\text { Renal Drug Cost (tacrolimus } 0.25 \mathrm{mg} \text { daily; MMF } 2 \mathrm{~g} \\
\text { daily, and prednisolone } 30 \mathrm{mg} \text { daily for } 90 \text { days) }\end{array}$ & 2103 & IMS PADDS database 2015 & & \\
\hline \multicolumn{5}{|l|}{ Procedure costs } \\
\hline Dialysis (for CKD 5 patients) & 17,580 & \multicolumn{3}{|c|}{$\begin{array}{l}\text { Dialysis cost of } \$ 17,280 \text { (Liu 2013) (adjusted for inflation) + monitoring cost } \\
\text { of } \$ 300\end{array}$} \\
\hline Transplant (for CKD 5 patients) & 11,825 & \multicolumn{3}{|c|}{$\begin{array}{l}\text { Transplant cost of } \$ 11,525 \text { (Zhao et al. 2012) (adjusted for inflation) + moni- } \\
\text { toring cost of } \$ 300\end{array}$} \\
\hline $\begin{array}{l}\text { Cost per hospital visit (assumed as unit cost of } \\
\text { physician visit in China)* }\end{array}$ & 25 & \multicolumn{3}{|c|}{ Chinese medical news website (Woodhead 2015) } \\
\hline \multicolumn{5}{|l|}{ Annual examination costs } \\
\hline For all antiviral therapies & 169.01 & \multicolumn{3}{|l|}{ Zhang et al. (2015) } \\
\hline For BSC & 175 & & & \\
\hline Cost for evaluation of new patient & 169 & & & \\
\hline
\end{tabular}

$A D V$ adefovir dipivoxil, BSC best supportive care, $C K D$ chronic kidney disease, ETV entecavir, $H B$ s $A g$ hepatitis $B$ surface antigen, $L A M$ lamivudine, $L D T$ telbivudine, $M M F$ mycophenolate mofetil, NA not applicable, TDF tenofovir

* This cost was used to calculate disease monitoring costs. For CKD stages 1 and 2, 3, and 4 and 5, we assumed 4, 8, and 12 yearly visits, respectively

were presented in US dollars (USD or \$), and wherever not available in USD, Ren Min Bi (RMB) was converted to USD at a rate of 6.22 RMB per USD.

\section{Results}

\section{Deterministic results}

Total discounted costs of the various treatment strategies (Table 7) were interpreted using the cost-effectiveness frontier (Fig. 2a, b). Cost-effectiveness frontier is a chart with the total discounted QALYs plotted along the $\mathrm{x}$-axis and the total discounted costs along the $\mathrm{y}$-axis. Every treatment is depicted on the chart with its total discounted costs and total discounted QALYs. In general, a treatment strategy appearing at the bottom right quadrant signifies that it generated large QALYs at a lower cost, whereas that located at the top left quadrant signifies that it generated few QALYs at a considerably high cost. The blue line connects the cost-effective treatments. Treatment options that lie above this line are not considered cost effective. At present, willingness to pay (WTP) in China is estimated to be approximately $\$ 23,000$ (3 times the gross domestic product [GDP] of China) (World Bank National Accounts Data 2015; Zhang et al. 2015).

When renal impact was not considered, without treatment sequencing, ADV and LDT were found to be more cost effective compared with other NUCs (Fig. 2a). The overall costs, QALYs and incremental cost-effectiveness ratios (ICERs) are presented in Table 7 . Amongst the strategies with treatment sequencing, $\mathrm{LDT} \rightarrow \mathrm{ADV}$ 
Table 7 Total discounted costs and QALYs for the treatment strategies

\begin{tabular}{|c|c|c|c|c|c|c|}
\hline \multirow[t]{2}{*}{ Treatment strategy } & \multicolumn{3}{|c|}{$\begin{array}{l}\text { Cost-effectiveness analysis results without considering } \\
\text { renal impact }\end{array}$} & \multicolumn{3}{|c|}{$\begin{array}{l}\text { Cost-effectiveness analysis results considering } \\
\text { renal impact }\end{array}$} \\
\hline & Cost (\$) & QALYs & $\begin{array}{l}\text { ICER with respect to } \\
\text { next best option }\end{array}$ & Cost (\$) & QALYs & $\begin{array}{l}\text { ICER with respect } \\
\text { to next best option }\end{array}$ \\
\hline \multicolumn{7}{|l|}{ Without sequencing } \\
\hline $\mathrm{BSC}$ & 45,234 & 12.40 & - & 46,171 & 12.40 & - \\
\hline LAM & 47,838 & 12.99 & ED & 48,679 & 12.99 & ED \\
\hline LDT & 49,620 & 13.60 & 4066 & 50,257 & 13.60 & 3398 \\
\hline ADV & 47,963 & 13.20 & 3435 & 52,423 & 13.20 & $\mathrm{D}$ \\
\hline ETV & 50,640 & 13.71 & $\mathrm{D}$ & 51,248 & 13.71 & $\mathrm{D}$ \\
\hline TDF & 64,413 & 13.27 & $\mathrm{D}$ & 65,291 & 13.27 & D \\
\hline LDT + ADV & 51,829 & 13.66 & $\mathrm{D}$ & 52,446 & 13.66 & $\mathrm{D}$ \\
\hline LDT + TDF & 59,267 & 12.78 & $\mathrm{D}$ & 60,114 & 12.78 & $\mathrm{D}$ \\
\hline \multicolumn{7}{|l|}{ With sequencing } \\
\hline $\mathrm{LAM} \rightarrow \mathrm{ADV}$ & 48,878 & 13.18 & D & 54,976 & 13.18 & D \\
\hline $\mathrm{ADV} \rightarrow \mathrm{LAM}$ & 48,231 & 13.17 & $\mathrm{D}$ & 54,560 & 13.17 & $\mathrm{D}$ \\
\hline $\mathrm{LDT} \rightarrow \mathrm{ADV}$ & 50,275 & 13.72 & 5774 & 50,868 & 13.72 & 5385 \\
\hline $\mathrm{ETV} \rightarrow \mathrm{ADV}$ & 50,819 & 13.74 & 27,205 & 51,422 & 13.74 & 27,741 \\
\hline
\end{tabular}

$A D V$ adefovir dipivoxil, $B S C$ best supportive care, $D$ dominated, $E D$ extended dominance, $E T V$ entecavir, ICER incremental cost-effectiveness ratio, $L A M$ lamivudine, $L D T$ telbivudine, $Q A L Y$ quality-adjusted life-year, TDF tenofovir

was cost effective. Interestingly, ETV $\rightarrow$ ADV sequence may appear cost effective as it generates higher QALYs; however, this strategy has a high ICER $(\$ 27,205)$ which is above the acceptable WTP in comparison to the LDT $\rightarrow$ ADV strategy.

When renal impact was considered, LDT and LDT $\rightarrow$ ADV strategies (with or without sequencing) appeared to be better in terms of cost effectiveness. For example, the ICER of LDT to BSC was lowered from \$4066 to \$3398 (Table 7).

\section{Probabilistic sensitivity analysis (PSA)}

The uncertainty of the cost-effectiveness results for a range of WTP thresholds were interpreted using costeffectiveness acceptability (CEAC) curves. For both scenarios, LDT $\rightarrow$ ADV sequence was cost effective with $51 \%$ probability even at willingness to pay of $\$ 20,000$. The next best scenario was the combination treatment of ETV and ADV, which was cost effective with approximately $43 \%$ probability (Fig. 3a, b).

\section{Discussion}

$\mathrm{CHB}$ is one of the most common causes of chronic liver disease, cirrhosis and HCC worldwide (Lavanchy 2004; McMahon 2005). In CHB patients, glomerulonephritis is an important extrahepatic manifestation of the viral infection (Chan 2010). Particularly, with aging, several patients present with comorbidities and various degrees of functional renal impairment (Deterding et al. 2011; Ha et al. 2009; Lai et al. 1991). Since the clinical management of CHB is mainly based on NUC therapy, there is a need for preservation of renal function in these patients. Such an outcome could be achieved by inclusion of NUCs with minimal nephrotoxicity in the treatment strategy. Especially in an evolving healthcare setting such as China, where real-world use of NUCs is primarily driven by costs along with clinical efficacy evidence (Fung et al. 2011), treatment strategy may be guided by robust pharmacoeconomic evidence.

Previous studies have reported ETV as the most costeffective NUC and advocated its use as a first-line antiviral therapy/preferred treatment option in patients with CHB (Wu et al. 2010; Wu et al. 2012) in Chinese healthcare settings. However, treatment and disease-related transition rates in these studies were primarily obtained from the literature using cohorts from different countries, which may affect the generalizability of the results and may not accurately reflect the situation in China. Moreover, these studies did not consider the long-term clinical outcomes associated with use of NUCs e.g. renal impact or development of drug resistance.

A recent study by Zhang et al. used a more systematic approach to identify the registered clinical trials that were based on Chinese populations and conducted meta-analyses to derive the parameter inputs (Zhang et al. 2015). The present model included inputs used by Zhang et al., to ensure that parameters reflect a realworld Chinese patient population. Long-term renal complications and drug resistance were modeled in this patient cohort, and combination and sequence therapies 


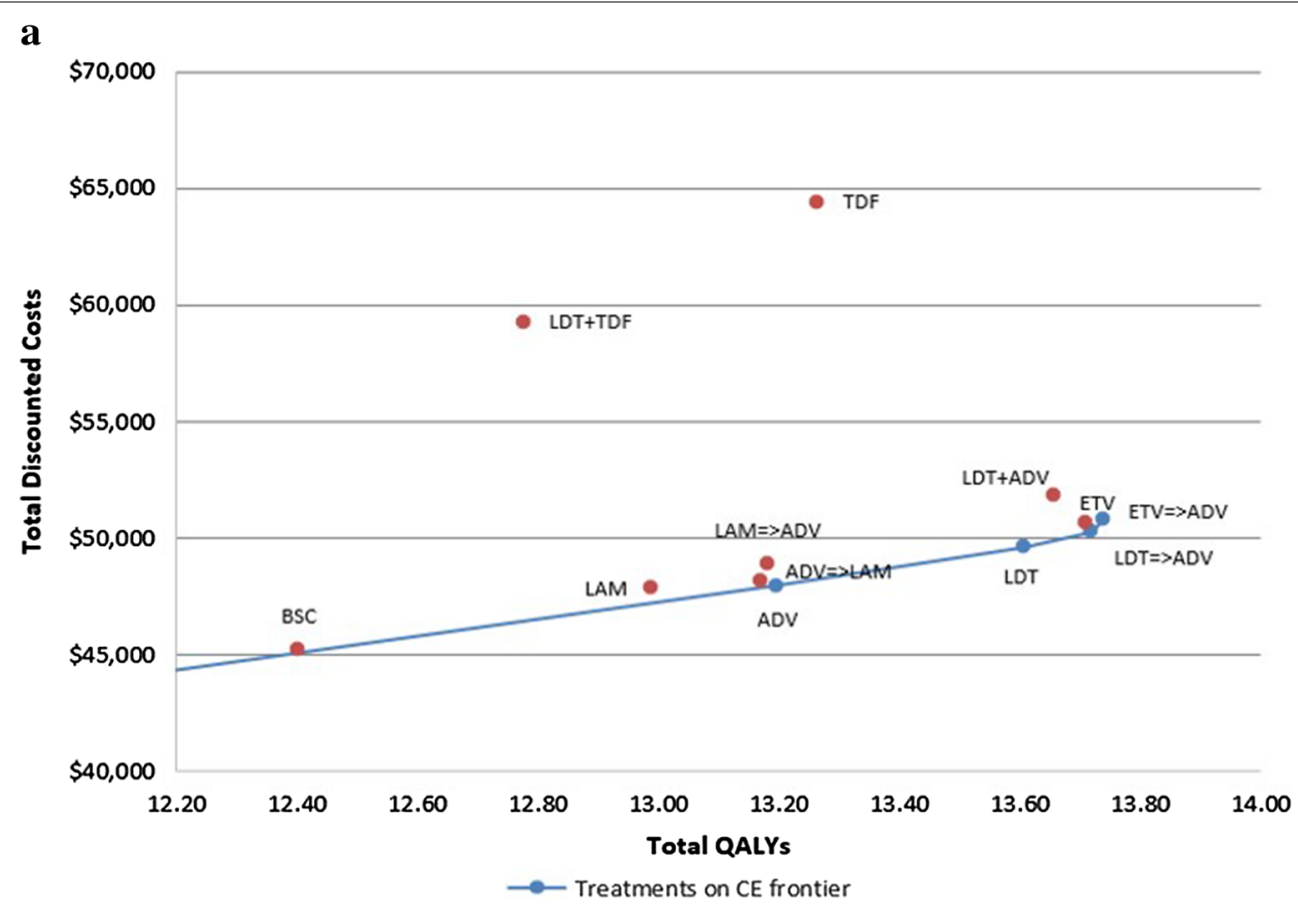

b

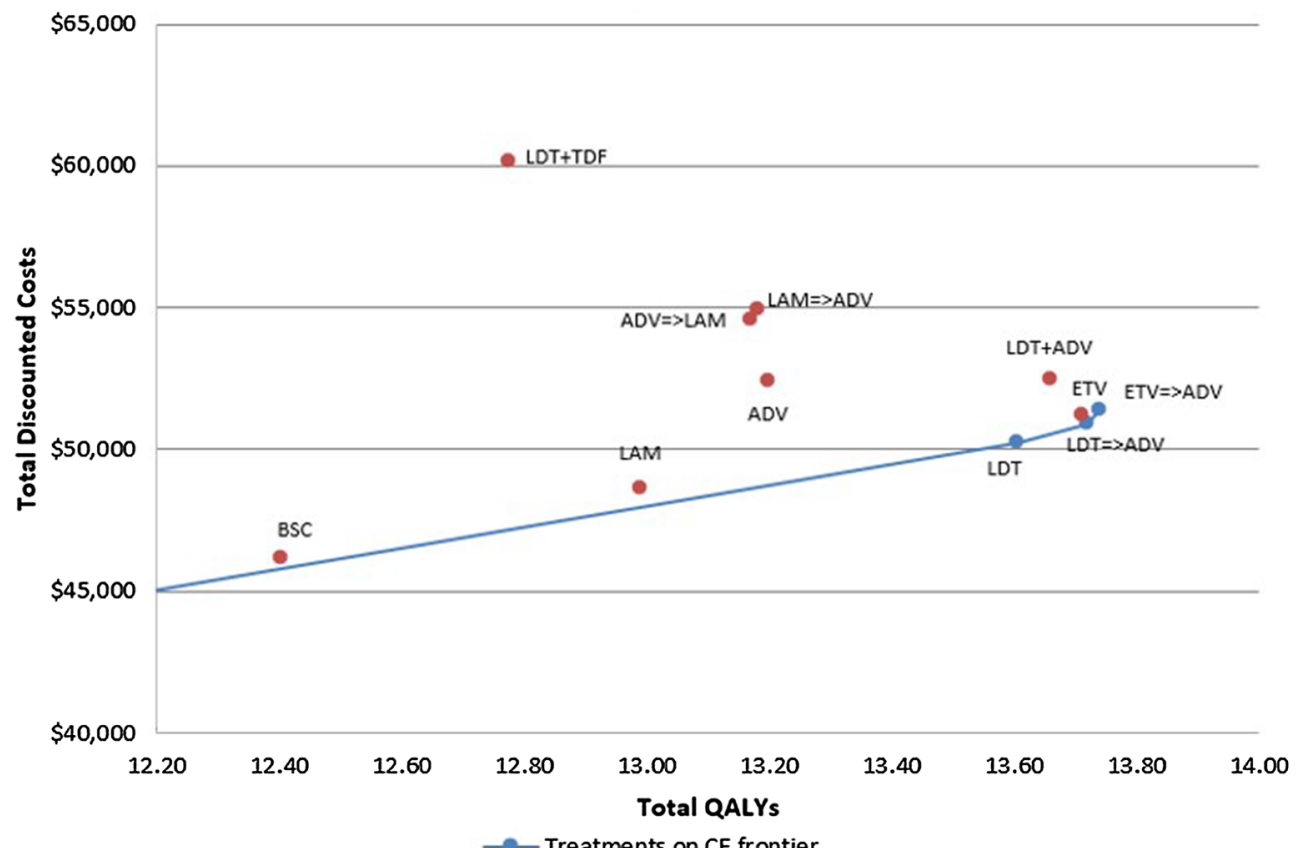

$\rightarrow$ Treatments on CE frontier

Fig. 2 Cost-effectiveness frontier a without renal impact and $\mathbf{b}$ including renal impact. ADV adefovir dipivoxil, BSC best supportive care, CE costeffectiveness, ETV entecavir, LAM lamivudine, LDT telbivudine, QALY quality-adjusted life-year, TDF tenofovir

of NUCs were considered in the analysis. In addition to including similar model inputs as those in the study by Zhang et al., the present study also included additional model parameters such as resistance profiles of NUCs and annual changes in eGFR with various treatments. Thus, the findings of the present analysis more closely reflect the clinical conditions of Chinese patients in realworld settings. 


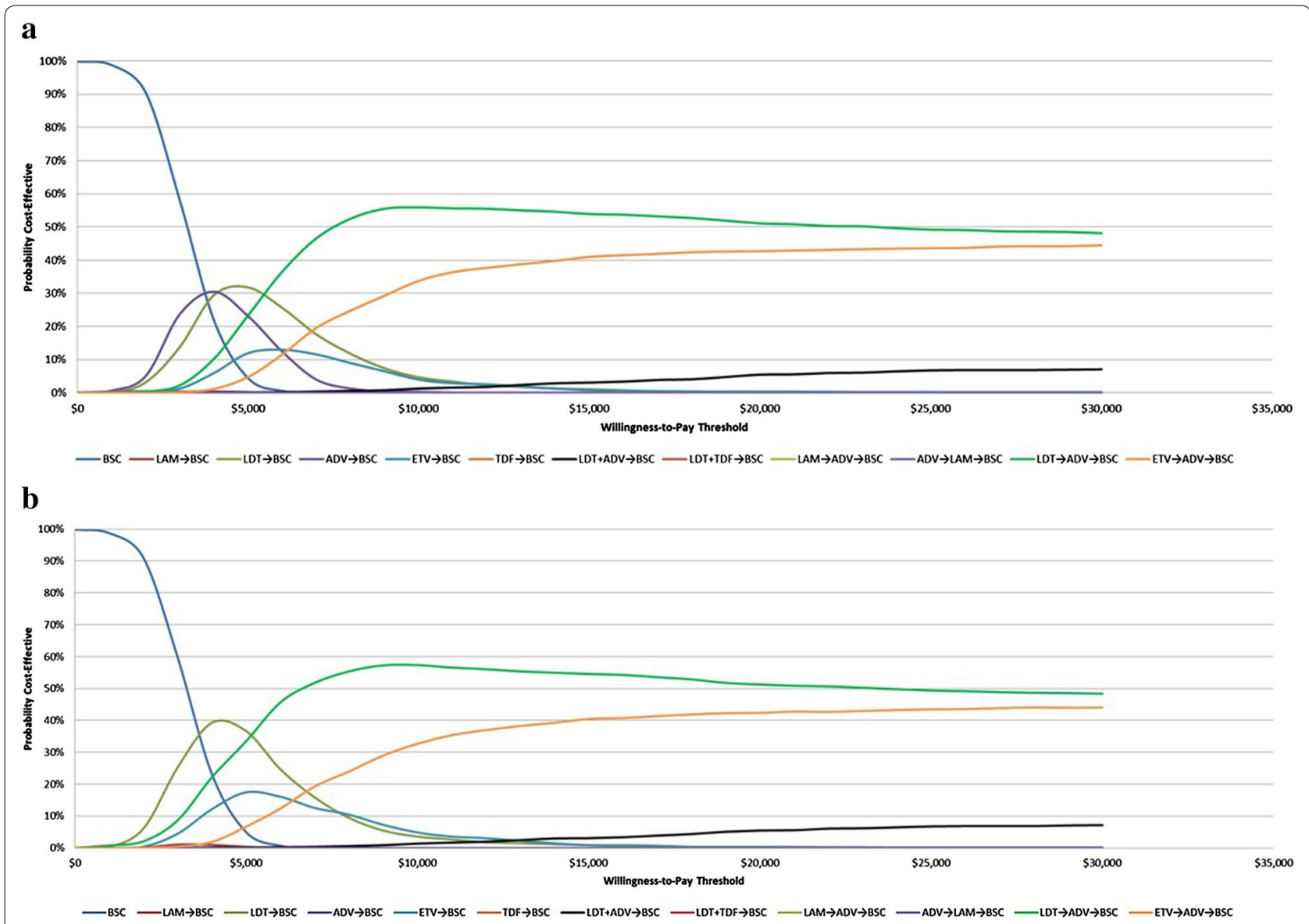

Fig. 3 Cost-effectiveness acceptability curve $\mathbf{a}$ without renal impact and $\mathbf{b}$ with renal impact. ADV adefovir dipivoxil, BSC best supportive care, ETV entecavir, LAM lamivudine, LDT telbivudine, TDF tenofovir

In the study by Zhang et al., treatment with ETV generated the highest number of QALYs, resulting in 10.8 QALYs compared with the next best result of 9.8 QALYs with LDT (Zhang et al. 2015). The present analysis showed QALY gain of 0.02 for ETV versus LDT (Table 7). In our model, there is a reduced difference in the rate of virologic resistance between LDT and ETV. Therefore, patients stayed longer on LDT compared with Zhang's analysis, and accordingly more patients moved to the inactive carrier state with LDT treatment. The benefit of ETV in terms of lesser resistance was apparently offset by LDT's impact on moving patients to the inactive carrier state. Thus, both regimens appeared similar in terms of QALYs in the current analysis. Another factor that contributed to QALY gain in Zhang et al. was virologic response. As ETV had a higher virologic response than LDT, patients spent more time in the response state, thereby contributing to QALYs. This factor was not considered in our model.

In a real-world Chinese healthcare setting, treatment with NUCs leads to the development of resistance, resulting in a switch to the next best therapy (Chinese Society of Hepatology and Chinese Society of Infectious Diseases and Chinese Medical Association 2011). The results of this model indicated that LDT $\rightarrow$ ADV was the most cost-effective treatment strategy. Other real-world studies in Chinese populations have also reported findings that support the results of this pharmacoeconomic analysis. In a retrospective study conducted in $\mathrm{CHB}$ patients from China, the renoprotective effect of LDT was found to be superior to that of ADV when both were used as monotherapies for 1 year (Li et al. 2012). Similar findings were reported in other studies in the Chinese population (Gane et al. 2014; Wang et al. 2013). Furthermore, a recent prospective cohort study provided evidence that in the Chinese population, prolonged LDT therapy resulted in an improved eGFR, whereas ADV therapy was associated with a decreased eGFR and both LAM and ETV therapies did not significantly influence eGFR (Qi et al. 2015). As renal protection is an important treatment-related concern in CHB patients (Deray et al. 2015), LDT offers clinically relevant efficacy and has a safety profile that may make it a possible therapeutic option for high-risk 
patients. In addition, clinical practice guidelines recommend the use of LDT in patients at an increased risk of renal impairment (Deray et al. 2015). The findings of the present analysis are in congruence with the real-world evidence (Gane et al. 2014; Wang et al. 2013), confirming the favorable clinical profile of LDT compared with other NUCs because of its lower renal toxicity. The findings of this study would enable Chinese payers to make evidencebased justifiable decisions.

\section{Limitations}

The present model has several limitations. The methodology adopted in this analysis was that of a transition state model that focused on HBeAg seroconversion. This approach is entirely based on the observations from $\mathrm{HBeAg}$-positive patients and may not be relevant for HBeAg-negative patients. For a few safety inputs, particularly eGFR, the evidence was sparse, and the numeric values used in the model were not derived from a metaanalytic synthesis. Furthermore, disutility due to renal function is expected to be different for patients in a CHB state versus patients in a decompensated cirrhosis state. Because of the lack of granular data, the current study could not model the differential utilities for patients in a CHB state versus those in decompensated cirrhosis state. Thus, the current analysis represents a conservative assessment or an underestimate of the cost effectiveness of LDT given its association with improved renal function.

\section{Conclusion}

In this pharmacoeconomic evaluation, LDT treatment proved to be cost effective for CHB in Chinese healthcare settings. Considering the impact of NUCs on renal function, overall costs for all evaluated treatment options were increased. However, the increase for LDT was comparatively small.

\section{Authors' contributions}

PG and KH designed the research. SB and PG conducted the analysis. All authors contributed to the acquisition, analysis and interpretation of data. All authors read and approved the final manuscript.

\section{Author details}

${ }^{1}$ Novartis Healthcare Pvt. Ltd., Hyderabad, India. ${ }^{2}$ Novartis Pharma AG, Basel, Switzerland. ${ }^{3}$ Novartis Pharmaceuticals Corporation, East Hanover, NJ, USA.

\section{Acknowledgements}

This analysis was funded by Novartis Pharma AG.

\section{Competing interests}

Surbhi Banerjee and Praveen Gunda are employees of Novartis Healthcare Pvt. Ltd. Roxana F. Drake is an employee of Novartis Pharma AG. Kamal Hamed is an employee of Novartis Pharmaceuticals Corporation.

\section{Human and animal rights}

This article is based on previously conducted studies and does not involve any new studies of human or animal subjects performed by any of the authors.
Received: 21 February 2016 Accepted: 28 September 2016

Published online: 05 October 2016

\section{References}

Almeida AM, Silva AL, Brandao CM et al (2012) Cost-effectiveness of nucleoside/nucleotide analogues in chronic hepatitis B. Rev Saude Publica 46(6):942-949

Biazar T, Yahyapour Y, Hasanjani Roushan MR et al (2015) Relationship between hepatitis B DNA viral load in the liver and its histology in patients with chronic hepatitis B. Casp J Intern Med 6(4):209-212

Blumenthal D, Hsiao W (2015) Lessons from the East-China's rapidly evolving health care system. N Engl J Med 372(14):1281-1285

Chan TM (2010) Hepatitis B and Renal Disease. Curr Hepat Rep 9(2):99-105

Chang TT (2009) On-treatment monitoring of HBV DNA levels: predicting response and resistance to oral antiviral therapy at week 24 versus week 48. Hepatol Int 3(Suppl 1):16-23

Chinese Society of Hepatology and Chinese Society of Infectious Diseases, Chinese Medical Association (2011) The guideline of prevention and treatment for chronic hepatitis B (2010 version). Zhonghua Liu Xing Bing Xue Za Zhi 32(4):405-415

Deray G, Buti M, Gane E et al (2015) Hepatitis B virus Infection and the Kidney: renal abnormalities in HBV Patients, antiviral drugs handling, and specific follow-up. Advances in Hepatology 2015:1-11

Deterding K, Lampe N, Reijnders J et al (2011) 366 prevalence and severity of kidney dysfunction in patients with chronic hepatitis B in Europe: data from the European Virgil cohort. J Hepatol 54(1):147

Fung J, Lai CL, Seto WK, Yuen MF (2011) Nucleoside/nucleotide analogues in the treatment of chronic hepatitis B. J Antimicrob Chemother 66(12):2715-2725

Gane EJ, Deray G, Liaw YF et al (2014) Telbivudine improves renal function in patients with chronic hepatitis B. Gastroenterology 146(1):138-146

Ha NB, Ha NB, Garcia RT et al (2009) Renal dysfunction in chronic hepatitis B patients treated with adefovir dipivoxil. Hepatology 50(3):727-734

He J, Bowen JM, Xie F, Goeree R (2012) Cost-effectiveness analysis of antiviral treatments for HBeAg-positive chronic hepatitis B in Canada. Value Health 15(6):894-906

Hou J, Yin YK, Xu D et al (2008) Telbivudine versus lamivudine in Chinese patients with chronic hepatitis $B$ : results at 1 year of a randomized, double-blind trial. Hepatology 47(2):447-454

Hou JL, Gao ZL, Xie Q et al (2015) Tenofovir disoproxil fumarate vs adefovir dipivoxil in Chinese patients with chronic hepatitis B after 48 weeks: a randomized controlled trial. J Viral Hepat 22(2):85-93

Lai KN, Li PK, Lui SF et al (1991) Membranous nephropathy related to hepatitis B virus in adults. N Engl J Med 324(21):1457-1463

Lavanchy D (2004) Hepatitis B virus epidemiology, disease burden, treatment, and current and emerging prevention and control measures. J Viral Hepat 11(2):97-107

Levy AR, Kowdley KV, lloeje U et al (2008) The impact of chronic hepatitis $B$ on quality of life: a multinational study of utilities from infected and uninfected persons. Value Health 11(3):527-538

Li X, Zhong C, Yang S et al (2012) Influence of adefovir dipivoxil or telbivudine monotherapy on renal function of patients with chronic hepatitis B. Nan Fang Yi Ke Da Xue Xue Bao 32(6):826-829

Liaw YF (2009) HBeAg seroconversion as an important end point in the treatment of chronic hepatitis B. Hepatol Int 3(3):425-433

Liaw YF, Gane E, Leung N et al (2009) 2-Year GLOBE trial results: telbivudine Is superior to lamivudine in patients with chronic hepatitis B. Gastroenterology 136(2):486-495

Liu ZH (2013) Nephrology in china. Nat Rev Nephrol 9(9):523-528

McMahon BJ (2005) Epidemiology and natural history of hepatitis B. Semin Liver Dis 25(Suppl 1):3-8

National Health and Family Planning Commission of the People's Republic of China (2015) http://www.moh.gov.cn/publicfiles/business/htmlfiles/ mohkjjys/s3578/201005/47399.htm. Accessed 3 Oct 2016

Ng CJ, Low WY, Wong LP, Sudin MR, Mohamed R (2013) Uncovering the experiences and needs of patients with chronic hepatitis B infection at diagnosis: a qualitative study. Asia Pac J Public Health 25(1):32-40 
Piratvisuth T, Komolmit P, Tanwandee T et al (2013) 52-week efficacy and safety of telbivudine with conditional tenofovir intensification at week 24 in HBeAg-positive chronic hepatitis B. PLoS ONE 8(2):e54279

Qi X, Wang JY, Mao RC, Zhang JM (2015) Impact of nucleos(t)ide analogues on the estimated glomerular filtration rate in patients with chronic hepatitis B: a prospective cohort study in China. J Viral Hepat 22(1):46-54

Robotin MC (2011) Hepatitis B prevention and control: lessons from the East and the West. World J Hepatol 3(2):31-37

Sarin SK, Kumar M, Lau GK et al (2016) Asian-Pacific clinical practice guidelines on the management of hepatitis B: a 2015 update. Hepatol Int 10(1):1-98

Shepherd J, Jones J, Takeda A, Davidson P, Price A (2006) Adefovir dipivoxil and pegylated interferon alfa-2a for the treatment of chronic hepatitis B: a systematic review and economic evaluation. Health Technol Assess 10(28):iii-iv, xi-xiv, 1-183

Spackman DE, Veenstra DL (2008) A cost-effectiveness analysis of currently approved treatments for HBeAg-positive chronic hepatitis B. Pharmacoeconomics 26(11):937-949

Sun J, Xie Q, Tan D et al (2014) The 104-week efficacy and safety of telbivudinebased optimization strategy in chronic hepatitis B patients: a randomized, controlled study. Hepatology 59(4):1283-1292

Tattersall J, Dekker F, Heimburger O et al (2011) When to start dialysis: updated guidance following publication of the Initiating Dialysis Early and Late (IDEAL) study. Nephrol Dial Transplant 26(7):2082-2086

Tsai MC, Chen CH, Tseng PL et al (2016) Comparison of renal safety and efficacy of telbivudine, entecavir and tenofovir treatment in chronic hepatitis B patients: real world experience. Clin Microbiol Infect 22(1): 95.e91-97

Vellozzi C, Averhoff F (2016) An opportunity for further control of hepatitis B in China? Lancet Infect Dis 16(1):10-11

Wang Y, Thongsawat S, Gane EJ et al (2013) Efficacy and safety of continuous 4-year telbivudine treatment in patients with chronic hepatitis B. J Viral Hepat 20(4):e37-e46

Wong GL, Wong VW, Chan HL (2014) Combination therapy of interferon and nucleotide/nucleoside analogues for chronic hepatitis B. J Viral Hepat 21(12):825-834
Woodhead M (2015) How much does it cost to go to the doctor in China? http://www.chinesemedicalnews.com/2015/04/how-much-does-it-costto-go-to-doctor.html. Accessed 3 Oct 2016

World Bank National Accounts Data (2015) World Bank GDP per capita. http:// data.worldbank.org/indicator/NY.GDP.PCAP.CD?locations=CN. Accessed 3 Oct 2016

World Health Organization (2012) Global health observatory data repository. http://apps.who.int/gho/data/?theme=main\&vid=60340. Accessed 3 Oct 2016

World Health Organization (2015) Hepatitis B. http://www.who.int/mediacentre/factsheets/fs204/en/. Accessed 3 Oct 2016

Wu B, Li T, Chen H, Shen J (2010) Cost-effectiveness of nucleoside analog therapy for hepatitis B in China: a Markov analysis. Value Health 13(5):592-600

Wu B, Shen J, Cheng H (2012) Cost-effectiveness analysis of different rescue therapies in patients with lamivudine-resistant chronic hepatitis B in China. BMC Health Serv Res 12(1):385

Yu R, Fan R, Hou J (2014) Chronic hepatitis B virus infection: epidemiology, prevention, and treatment in China. Front Med 8(2):135-144

Yuen MF, Seto WK, Fung J et al (2011) Three years of continuous entecavir therapy in treatment-naive chronic hepatitis B patients: VIRAL suppression, viral resistance, and clinical safety. Am J Gastroenterol 106(7):1264-1271

Yuen MF, Ahn SH, Chen DS et al (2016) Chronic hepatitis B virus infection: disease revisit and management recommendations. J Clin Gastroenterol 50(4):286-294

Zeuzem S, Gane E, Liaw YF et al (2009) Baseline characteristics and early on-treatment response predict the outcomes of 2 years of telbivudine treatment of chronic hepatitis B. J Hepatol 51(1):11-20

Zhang C, Ke W, Gao Y et al (2015) Cost-effectiveness analysis of antiviral therapies for hepatitis B e antigen-positive chronic hepatitis B patients in China. Clin Drug Investig 35(3):197-209

Zhao W, Zhang L, Han S et al (2012) Cost analysis of living donor kidney transplantation in China: a single-center experience. Ann Transplant 17(2):5-10

\section{Submit your manuscript to a SpringerOpen ${ }^{\circ}$ journal and benefit from:}

- Convenient online submission

- Rigorous peer review

- Immediate publication on acceptance

- Open access: articles freely available online

- High visibility within the field

- Retaining the copyright to your article

Submit your next manuscript at springeropen.com 